the deviation and dispersion required are large, the deviation amounting to over $300^{\circ}$; that is to say, the ray of light is bent through almost a complete circle; the light from stars is dim, and many prisms cannot be employed to widen out the spectrum, but in the case of the sun, there is light sufficient to give us a bright spectrum after it has been enormously dispersed.

Figs. 31 and 32 show a very powerful spectroscope to be attached to the telescope for observing the spectrum of the sun. One peculiarity of the instrument in Fig. 33 is that the ray of light having passed once through the lower part of the train of prisms, is received by a rightangled prism, which totally reflects the light twice, sending the ray of light back through the upper part of the same prisms, when it is again refracted; we thus have, by using these prisms, the same effect as if thirteen prisms had been employed. The ray of light enters the

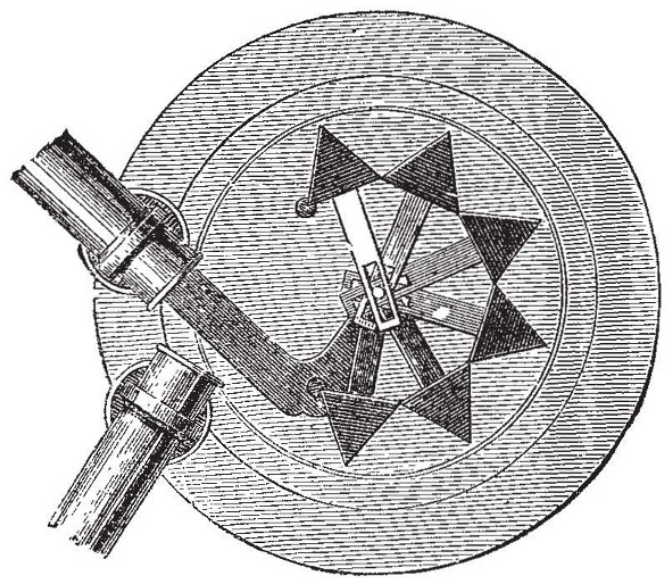

Fig. 33.-Autonatic arrangement for securing the minimun deviation of the obicrved ray.

instrument by the lower tube, and after passing first through the lower half of the prisms, and back through the upper half, is received in the upper tube, and reflected upwards for convenience of observation. These prisms are so arranged, that whatever part of the spectrum is being observed, they are always at the angle of minimum deviation for this part of the spectrum, a very important point, as if this is not attended to the spectrum loses much of its brilliancy and sharpness. This is done either by attaching the prisms to a spring of ebonite or gun metal moving on a fixed point near the first prism of the series, as in the arrangement shown, or each prism may be attached to a radial bar acting on a central pin, as shown in Fig. 33.

J. NORMAN LOCKYER

(To be continued.)

\section{HUNTERIAN LECTURES BY PROF. FLOWER}

\section{LECTURES IV. V. VI.}

T $\mathrm{T}$ will not be necessary in describing the fossil remains 1 of mammalia to devote any time to the consideration of the Monotremata, for though it might have been supposed that these animals, the Echidna and Duck-bill, on account of their being the lowest in the scale, would have been largely represented in ancient times, evidence to that effect has not been forthcoming. In the post-pliocene of Australia, the lower end of the humerus of a large Echidna, was found by Mr. Krefft, curator of the Museum at Sydney, and that is apparently the only recorded specimen from the class. With regard to marsupial animals the case is very different, and the remains prove that their geographical distribution formerly was not at all what it is now, when they are confined to Australia, the Austro-malay Archipelago, and South America. The family may be classified by the teeth or by the feet. According to the former method the Kangaroos, Phalangers, Koalas, in which there are only two lower incisors, without persistent pulps, form one herbivorous group ; the Wombats a second ; and those with more than two lower incisors, including the Bandicoots, Dasyures, Thylacine, and Opposums, a third carnivorous section. If the structure of the feet be taken as the main point, the tendency to the reduction of the second and third digits places the Bandicoots with the Kangaroos, instead of with the Dasyures, and does not otherwise modify the arrangement. The at first sight great difference between the molar teeth of the Thylacine and the Kangaroo can be easily bi idged over by a comparison of intermediate forms; looking for instance at an upper molar in the latter, its crushing surface presents two broad ridges, with an intermediate depression, in which there is an oblique groove. In the Thylacine there is a central large, and two lateral smaller tubercles, with a band connecting the medium with one of them. There is also a small posterior and two very small anterior tubercles in the cingulum. I' Perameles the molar presents two rows in a double crescent, in front of which are four minute processes, which represent those of the cingulum of the Thylacine, the crescents being representatives of the big tubercles. In the Kangaroo Rats the tubercles alone remain, and in the Kangaroo these blend to form the ridges.

Respecting the fossil forms, those from the Purbeck beds have been thoroughly worked out by Prof. Owen. With the exception of Plagianlax they belong to the polyprotodont division, and nearly all have more than seven teeth of the molar series, Triconodon and Triacanthodon being the exceptions, they also being peculiar and differing from all existing Marsupials in having four premolars and three molars. There is no evidence to show whether there was any succession of the teeth. Plagiaulax has been the subject of one of the most important controversies in connection with palcontology, between Prof. Owen and the late Dr. Falconer, the former maintaining that it was carnivorous, eating the lizards found with it; Dr. Falconer that it was herbivorous and allied to Hypsiprymnus. The fact of its having only two lower incisors, and that the molars are hypsiprymnine in form tends to show that it mus have had some relation to the herbivorous group, and shows that at so ancient a date the family had already divided in the manner that we now find it.

The tertiary Marsupialia must next be considered. In the Eocene gypsum of Montmartre several small skeletons have been found, clearly referable to the Opossums, and with a similar dentition, from which Cuvier was able to classify them correctly and predict the existence of marsupial bones in the uncovered skeletons. From Auvergne three similar miocene species have been described, and in England Mr. Charlesworth has, on undoubtedly insufficient evidence, referred a premolar to the same genus, Dideiphys. The Yale College expedition have obtained, among the large number of bones that they have collected, some which Prof. Marsh thinks are Marsupial. In the Pliocene there have not been any fossil remains of this sub-class yet obtained, but many in the Quaternary period. In the Brazilian caves Opossums have been found in abundance, and in the Wellington Valley and many other parts of Australia extremely interesting forms have been obtained, which must be referred to more fully. Prof. Owen has studied them in great detail. The remains may be divided into two divisions; (I), those allied to existing genera ; and (2), those not now represented. With regard to the former it is interesting to observe that the Thylacine and Ursine Dasyure, now restricted to Tasmania, at one time abounded on the mainland. There are also remains of enormous Wombats and 
Kangaroos, and the Kangaroo-rats were well represented. Of the genera now unrepresented Diprotodon was one of the largest ; it was the size of the biggest existing Rhinoceros; only one species is known. Excepting the skull the bones are not well known, the feet and several other parts not having been obtained. There was a strong descending process from the zygoma. The dental formula is represented thus : i. $\frac{3}{\mathrm{I}}$. c. ${ }_{0}^{-} \cdot \mathrm{m} \cdot \frac{\mathrm{I}+4}{1+4}$. The middle anterior incisors and those of the lower jaw closely resemble those of the Rodentia on a large scale; they grew from persistent pulps. The upper lateral incisors were small and had closed roots. Between them and the molars there was a gap. The molars were double crested, with four roots in the upper and two in the lower. Its dentition allies it with the Kangaroo, but from the bones that are known it is probable that its proportions were more that of the Wombat, the femur being longer than the tibia, and of the same length as the humerus. The femur was singularly compressed. Another genus, Nototherium, was still more extraordinary; it was first supposed to have no lower incisors, but this was subsequently proved to be incorrect. Mr. Macleay, after Prof. Owen's description of the genus from lower jaws only, obtained upper jaws of an animal, called by him Zygomaturus. Prof. Owen stated, and apparently with very good reason, that this was nothing but the upper part of the skull of his Nototherium. In this genus the zygoma is enormous in all directions and at the extreme anterior root has a descending process. Its dental formula is i. $\frac{3}{1}$. c. $\frac{0}{0} . \mathrm{m} . \frac{5}{5}$, resembling Diprotodon, except that the incisors in upper and lower jaws are all rooted. Three species have been described, and no bones of the body have been found. In the museum of the College there is an astragalus, very Wombat-like, and also an atlas which agree well in size with what would have been expected in such an animal, which for other reasons was probably intermediate between the Kangaroos and Wombats.

Thylacoles is the last of these extinct marsupials; none of the bones, except of the head, have been found ; the zygoma and the angle of the lower jaw are still unknown. As far as can be determined, it apparently approaches nearest to the koala. The teeth are quite peculiar to the genus; the dental formula is $\mathrm{i} \cdot \frac{\mathrm{I}}{3}$. c. ${ }_{\mathrm{O}}^{\mathrm{I}} \cdot \mathrm{p} \cdot \mathrm{m} . \frac{3}{\mathrm{I}} \cdot \mathrm{m} \cdot \frac{\mathrm{I}}{32}$ The incisors in both jaws are much as in the phalangers, the median being large and with closed roots. Then follow two small lateral teeth in the upper jaw, behind and internal to which is an almost hidden canine, partly covered posteriorly by two small premolars. The characteristic tooth, an enormous elongated and flattened last premolar comes next. This peculiar tooth is evidently that which replaces the only one lost in this class of animals, and which is always large, particularly in the kangaroo-rats. Internal to the posterior border of this tooth the minute true molar stands, just as in the cats. In the lower jaw two rudimentary teeth are sometimes present, followed by the peculiar large premolar, and that by two small molars. The muzzle was blunter than in most existing diprotodonts. The stunting of the molars is correlative with the great development of the extraordinary premolar undoubtedly. Prof. Gervais has taken a cast of the interior of the skull, and considers that the brain approaches the wombat most nearly. Prof. Owen originated and still strongly supports the idea that Thylacoles "was one of the fellest and most destructive of predatory beasts." Mr. Krefft, of Sydney, was the first to call his opinion in question, and he gave a conjectural restoration of the then unknown anterior part of the skull and incisor teeth, which subsequent discoveries have in great measure confirmed. No doubt its nearest alliances are with the phalangers and kangaroos, which are neither of them carnivorous. In the carnivorous marsupials, as in the cats, the canines are large and the incisors small. It is probable that the uniqueness of the dentition indicates a peculiar diet, perhaps some form of food, of a vegetable nature, which has disappeared, as has its consumer. Claws have been found, probably of this animal; they closely resemble those of the phalangers.

\section{NOTES}

Dr. DeBus has been appointed Professor of Chemistry at the new Naval College.

$\mathrm{IT}_{\mathrm{T}}$ is rumoured that Prof. James Thomson of Belfast will succeed to the Chair of Engineering at Glasgow University, vacant by the death of Prof. Macquorn Rankine.

Sir JoHn LuBBock will, to-night, at half-past eight, lay before the Society of Antiquaries the results of his researches during a tour last autumn respecting the site of Troy.

Accordrng to a Berlin telegram, another coal-field of apparently gigantic dimensions has been discovered in Central Asiathe Chodshent district, near Sir Darya.

THE Times understands that an intense magneto-electric light and an exceedingly powerful gaslight will shortly be exhibited simultaneously on the north and west sides of the upper part of the Westminster Clock. Tower. The current in the former will be generated by a comparatively novel and remarkable magneto-electric machine moved by steam power, which a high authority in this corntry pronounces to be a decided step in advance of every other machine of the kind. The latter is in operation at various lighthouses on the Irish coast, and may in favourable weather be seen at the distance of twenty-five miles. The exhibitors have proposed that the trial shall be made at their own cost, except in very trifling particulars.

WE learn with regret that Mr. J. Glaisher, F.R.S., has resigned the secretaryship of the Meteorological Society, an office which he has held continuously (except during his presidency) from the foundation of the society, of which he was one of the earliest promoters, in 1850 .

ThE Vice-Chancellor of Cambridge has appointed Prof. Tait, of Edinburgh University, Rede Lecturer for the ensuing year. Prof. Tait will deliver his lecture in the Easter term.

AN influential committee has been formed at Cambridge of members of the University and others for the purpose of having a portrait of Prof. Cayley painted and presented to Trinity College. A considerable, portion of the sum required has been already promised. The portrait, which is being painted by Mr. Lowes Dickenson, is of the same size as that of Sir William Thomson, by the same artist, that has been recently placed in the Combination Room of St. Peter's College. The movement is supported by all members of the University, irrespective of college, and other admirers of Prof. Cayley's mathematical discoveries; the only reason for the presentation of the portrait to Trinity (the professor's own) College being that there is no public building in the University appropriate for the reception of portraits of distinguished members of the University. Everyone will be pleased at the compliment which will thus be paid to the most illustrious English mathematician of the age. Subscriptions may be sent to the treasurer, William Walton, Esq., Trinity Hall.

AT the Annual Meeting of the Geological Society on February 21, the Wollaston Gold Medal was awarded to Sir Philip de Malpas Grey-Egerton, Bart., F.R.S.; the balance of the proceeds of the Wollaston Donation Fund to Mr. J. W. Judd, F.G.S.; the Murchison Medal to Mr. William Davies, of the British Museum; and the balance of the Murchison Fun.l to Prof, Oswald Heer of Ziuich. 